\title{
Public Transport to the Airport and Its Influence on Handling Process
}

\section{Martin Málek ${ }^{1}$, Jakub Hospodka ${ }^{1 *}$}

${ }^{1}$ Czech Technical University in Prague, Faculty of Transportation Sciences, Prague, Czech Republic

*Corresponding author: Czech Technical University in Prague, Faculty of Transportation Sciences, Horská 3, 12801 Prague, Czech Republic, Email: hospojak@fd.cvut.cz

\section{Abstract}

The article evaluates current system of weather information provision to pilots of commercial aircraft in flight. Specifically it focuses on what is provided in case of thunderstorms present in the terminal area opposed to what is needed from pilot's perspective for effective decision making. Contents and availability of aviation weather messages are considered and suggestions for optimization of information sources are made. Benefits of the provision of additional information containing the position of cumulonimbus clouds are explained on the examples of operational scenarios. The scenarios are based on historical weather data, however solutions and decisions are fictional. Explanation of different scenario solutions based on information available in the cockpit is provided and the consequences evaluated.

\section{Keywords}

aeronautical weather reports; landing forecast; thunderstorms; weather radar

\section{Introduction}

Today's development in information and communication technologies leads also to a rapid evolution of meteorology area, which deals with actual weather situation description and its projection into upcoming minutes. This projection can be based simply on extrapolating movement of precipitation areas using several successive weather radar images to determine position of dangerous weather in the order of minutes or dozens of minutes. Outputs from such short term forecast could be very valuable for aircraft pilots during flight, although it is not yet being widely used. To be more specific, in case of stormy weather, there are not many possibilities for aircraft crews to have access to area wide weather situation and forecast for immediate future with local accuracy. This information, although easily accessible through web browsers and mobile apps on the ground is not generally available aboard majority of today's commercial aircraft in flight, due to the lack of connection. In most airlines, the only source of weather information in flight is through the system of aeronautical meteorological messages, which are provided via VHF broadcast (ATIS, VOLMET) or data-link connections (ACARS). Other sources are onboard weather radar, air traffic controller weather avoidance information, other aircraft reports or visual cues. This sources however, may not always be specific enough, up to date and available when needed for effective decision making.

\section{Available sources in flight}




\subsection{Aeronautical weather messages}

Let's consider mostly used sources in the cockpit. METAR is the name for coded form of aerodrome routine report. It describes present weather situation at the airport. They are issued in periodical time intervals (usually every 60 or 30 minutes) and consist of a sequence of weather elements in a specific format. METARs can be supplemented by recent weather information and/or by a landing forecast, so called TREND. If some element of the report changes its value over a specified threshold or criteria during the time interval between the issues of subsequent routine METARs, new report must be made. This special irregular report is called SPECI. [1] The actual METAR or SPECI for particular airport is available in flight via ATIS, VOLMET broadcasts or data up link.

The TAF is a coded form of aerodrome forecast. They are issued in most cases every 6 hours and cover time interval of 30 hours. This interval can be also different, but according to ICAO standards, cannot be shorter than 6 hours. TAF format is very similar to METAR. The weather covered in METAR or TAF is the weather on the particular airport only. That means an area defined by a circle approximately $8 \mathrm{~km}$ wide or $16 \mathrm{~km}$ wide, when the phrase "in the vicinity" is used. [2] In flight, the actual TAF may not be possible to get when not equipped with data link service.

Storms, especially the convective type, are very difficult to forecast in long term. Today, there are only means to forecast, if some wider areas are going to be affected by storms with general time interval specification. The life cycle of a single convective storm cell in temperate climate usually ranges from several dozens of minutes up to few hours. [1] In typical "heat generated" summer stormy weather situations it is impossible to forecast location of storm cells in the order of hours in advance. The consequence is, the TAF can only specify general time interval with some probability that storms will affect particular airport. For example: "from 1600 to 2000 with $40 \%$ probability temporary thunderstorm with rain".

SIGMET is a meteorological warning about some specific potential danger to aircraft en route. The phenomena for which SIGMET must be issued are defined by ICAO regulations. For thunderstorms, the issue of SIGMET is mandatory only if it is accompanied by a specific characteristic that makes it more dangerous than usually, e.g. thunderstorms embedded in cloud layers, obscured, thunderstorms on squall line etc. "Usual" not specific thunderstorms do not need to be covered by SIGMET. [3] The areas covered by weather phenomena in SIGMET message are defined by geographical coordinates, which may often be difficult to interpret without some software able to draw the area into a map. Manually plotting several individual points into charts is time consuming and if the message is not received in advance during cruise flight, there may not be time enough to interpret the data before reaching terminal area. In flight, these messages are available via data link or VOLMET broadcast, but the second option is very impractical, due to the need to record lots of numerical data (geographical positions) Transmitting of such information in voice format can be very long and thus ineffective.

\subsection{Airborne weather radar}

On board weather radar is very important safety equipment. It scans the area in front of the aircraft and, with proper use, allows the flight crew to avoid areas with heavy precipitation accompanied by severe turbulence, icing and other dangers. However, the range at which it is possible to determine dangerous weather is limited. Also, due to the fact that the radar beam is oriented approximately horizontally against the ground, it does not show overall situation. In case of multiple storms, some may be located behind others in relation to the aircraft and the radar beam may not be strong enough to penetrate through strong reflections. The first storm, or line of storms, will cast a radar shadow thus making it impossible for the flight crew to determine if something is behind. [4] Together with limited range and angularly limited area of scan, the airborne weather radar itself does not always provide enough data for optimum avoidance route selection.

\section{Information missing}

\subsection{Lack of overall situation knowledge}

Actual METAR and TAF are most of the time the only information available for flight crew in advance. The problem is that these messages contain only description of situation at the aerodrome and its close surroundings. There is no source of information about the current situation in the wider area around the airport. Weather on arrival and approach routes and exact location of dangerous phenomena is missing. Pilots have to base their decisions only on airborne weather radar data or visual cues. They may be lacking the "big picture", the overall situation around the destination airport. This can lead to the selection of avoidance routes, which may not be optimal to the situation. I will present this idea on the following model situation example.

The Fig. 1 shows a screenshot of overall weather situation over Czech airspace from mobile weather radar data viewer. There is a line of thunderstorms spreading from the destination airport (LKPR) to the east. Runway in use is 24. For the arriving flight, the sources available are airborne weather radar and SPECI report broadcast on ATIS:

\section{SPECI LKPR 052105Z 04004KT 9999 TS FEW046CB}

17/13 Q1019 [5]

(SPECI Praha issued at 2105, wind 040 degrees 4 knots, visibility over $10 \mathrm{~km}$, thunderstorm, clouds few 4600 feet cumulonimbus, temperature 17, dew point 13 , QNH 1019)

Airborne weather radar display shows heavy precipitation line spreading from approximately 80 nautical miles east of airport in the western direction. The range of meaningful detection is up to the destination airport at first (from present 
position), than when flying along the magenta flight path (STAR route for runway 24), it is not possible to determine, if some weather is also behind the storm line to the north or further west of the airport due to the storms radar shadows. Flight crew thinks, that the storm line is spreading further to the west (indicated by grey cloud symbols), because they have no reason to think otherwise (no more sources of information). Based on what they have, their decision is to pass through the line by circumnavigating individual cells as they are not so severe to cause serious threat to the aircraft. However, some turbulence encounter will likely happen.

On the other hand, if the flight crew had previous access to the overall picture, they would probably take another route requesting ATC vectors or arrival route via west and north (blue line) as optimal and turbulence free option.

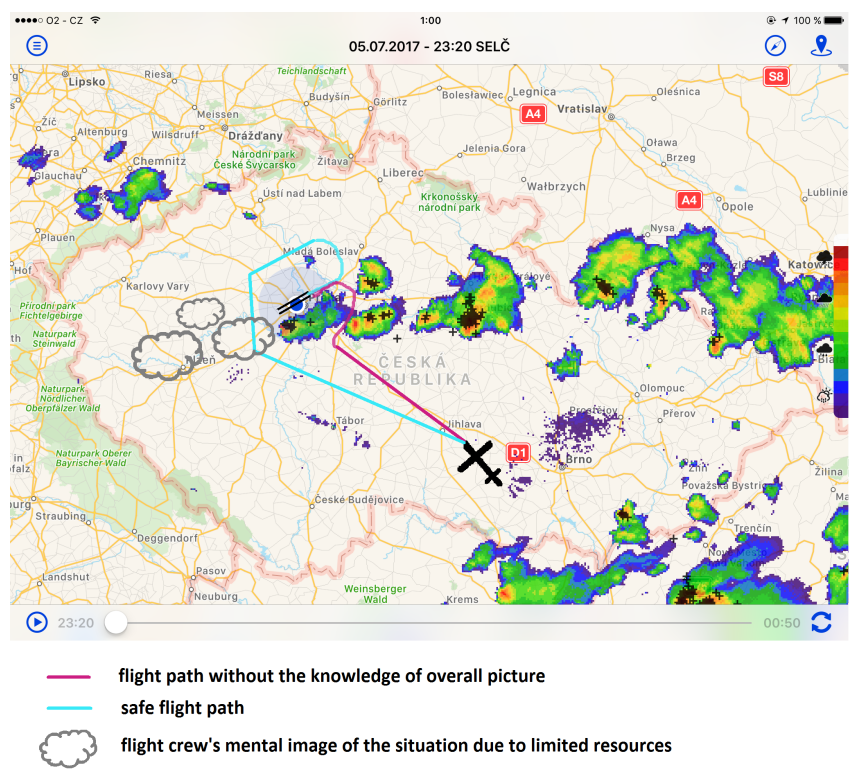

Figure 1. Scenario where storms are affecting standard arrival routes [6]

\subsection{Missing detailed time specification}

Main source of information about upcoming weather during landing is the METAR or SPECI with the landing forecast (TREND). The validity interval for TREND is 2 hours starting from the report issue time. The forecast uses either of change indicators: TEMPO (temporary) or BECMG (becoming). These indicators may be also supplemented by acronyms FM (from), TL (until) and AT (at, used only with BECMG). [3] However, exact time specification is not used very often in practice due to the requirement to maintain accuracy of this forecast during longer time interval without the need to issue another SPECI. When the storm is approaching the aerodrome, only general information is usually provided, e.g. TEMPO TSRA or BECMG TSRA. I will try to explain the value of detailed time information on another situation model.
In Fig. 2 there is a storm approaching Prague aerodrome (LKPR) from the south. The estimated time of arrival (ETA) for the flight is $1020 \mathrm{Z}$. At $0950 \mathrm{Z}$ they reach the distance 200 NM from the airport (point 1), where the VHF ATIS broadcast becomes available. The flight crew records following METAR information:

\section{METAR LKPR 010930Z VRB4KT 9999 SCT038 25/16 Q1016 TEMPO TSRA SCT030CB [7]}

(Praha Ruzyne METAR issued at 0930, wind variable 4 knots, visibility over 10 kilometers, clouds scattered 3800 feet, temperature 25, dew point 16, QNH 1016. Temporary thunderstorm with rain, scattered $3000 \mathrm{ft}$ cumulonimbus)

The TREND forecast in this message tells only, that thunderstorm is expected at some time during next 2 hours and in total will cover less than $50 \%$ of the time interval (will not last more than 1 hour) [2]. Considering this is the only information the pilots have, they continue towards destination airport (route 2). At 1010Z they detect on airborne weather radar heavy precipitation area over the destination. New ATIS information contains following:

\section{SPECI LKPR 011014 180/12KT 9999 TS SCT020CB BKN036 22/14 Q1017 [7]}

(Praha Ruzyne SPECI issued at 1014, wind 180 degrees 12 knots, visibility over $10 \mathrm{~km}$, thunderstorm, clouds scattered $2000 \mathrm{ft}$ cumulonimbus, broken $3600 \mathrm{ft}$, temperature 22, dew poin 14, QNH 1017)

Due to the thunderstorm present overhead the airport, the crew evaluates the landing at present moment as unsafe. They request holding and at $1015 \mathrm{Z}$ enters holding pattern. Apart from the fuel needed to reach the destination and the mandatory reserves the crew has another 30 minutes of fuel available for unexpected circumstances. They may use this fuel before mandatory diversion to the alternate aerodrome LKTB (Brno Turany). During the holding, the crew monitors the ATIS. The weather in Prague deteriorates, but no specific time of thunderstorm termination is specified in the messages. At 1035Z, the fuel expected after landing in Prague would reach the sum of final reserve and alternate fuel so no other holding is possible. Thunderstorm in Prague is still present so the decision to divert is made (route 3). Aircraft lands in Brno at 1055Z. After refueling and planning of the flight the aircraft continues to original destination (the storm moved away from the airfield at 1100Z, route 5). The time spent on the ground is approximately 1 hour. The landing in Prague in this case is $1215 \mathrm{Z}$.

Now let's consider the case the flight crew would have time specific landing forecast available at point 1 . For example: "becoming thunderstorm from $1015 \mathrm{Z}$ till 1100Z". Considering, that pilots know the earliest possible time of 
arrival (1020Z) and fuel available for holding up to 1035Z, the result would be the decision to make an intermediate landing on some airport en route (in this case the alternate LKTB is suitable, route 4), refuel and continue to destination after the weather improves (route 5). In this case, the aircraft would land at 10:05Z in Brno at 11:05Z would be ready and at $11: 25 Z$ could reach original destination.

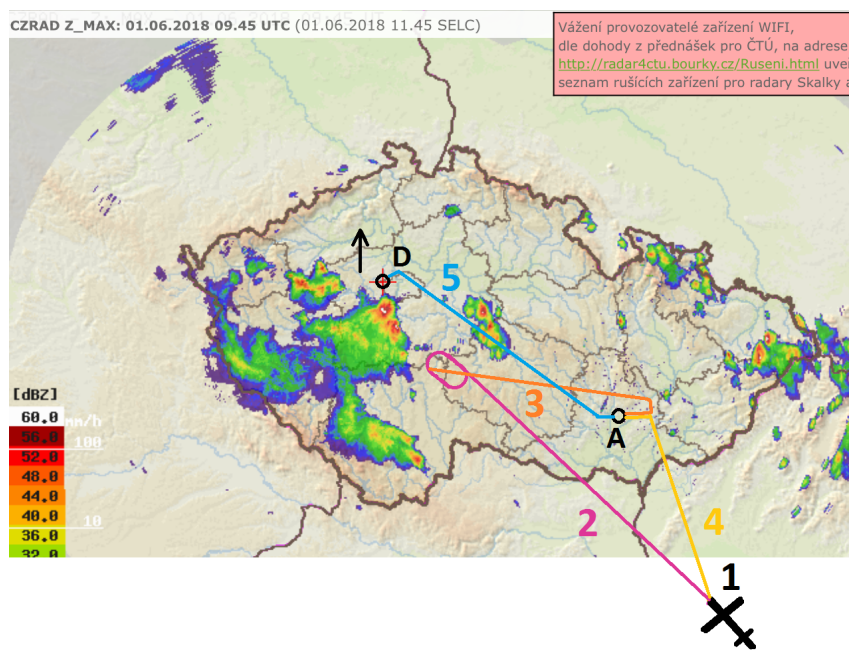

Figure 2. Scenario where thunderstorms pass over the destination airport [8]

Both decision variants differ significantly in fuel related costs and on time performance. In the first case, the airplane was airborne for 50 minutes extra. In the case of Boeing 737 it would mean approximately $2000 \mathrm{~kg}$ of extra fuel burn. This 50 minutes is also the difference in total delay which has an impact of time related operator costs.

\section{Possible solutions}

The overall weather situation can be provided to pilots via FIS-B (ADS-B In application). The problem is that new hardware would need to be equipped into current aircraft fleets. FIS-B service is currently available in United States only and is used mainly by general aviation. Airlines are not interested in this technology due to implementation costs and questionable profitability. [9] Another option is to provide the crew with internet access using their electronic flight bags. Some airlines today are starting to provide internet connection to the passengers. This would also solve the issue of access to the weather information for flight crews.

Considering specification of time in landing forecasts some work can be made. Contrary to the fact, that standard ICAO form of TREND forecast provides means how to specify exact time information using word FROM, TL and AT, it is not being widely used in practice. The reason behind may be that the TREND validity time interval is too long and high level of accuracy is required over a longer period of time. This could be solved by optimizing the requirements for accuracy depending on the time distance from issue of the message to the time of forecast. For longer time period, the accuracy would be less strict. For example: in the period of 15 minutes from time of issue, the requirement for accuracy of correct time prediction would be plus or minus 5 minutes in $90 \%$ of cases. However, in the period between 60 and 120 minutes from present the requirement could be plus or minus $15 \mathrm{~min}$ utes in $90 \%$ of cases. The accuracy should be set according to the actual weather forecasting capabilities.

Another solution can be the provision of new message type which would contain the time information as a supplement to TREND. Such message could be automatically generated from ground based weather radar system respectively the extrapolated future development images. Basically it would only specify the time when heavy precipitation will reach a certain position (airport) and when it will move away. Some threshold value of reflectivity corresponding to the red color on weather radar images would be set to determine which precipitation is heavy. The advantage of automatic system is, that it can generate new messages continuously (for example every minute) revising old data and maintaining high level of accuracy for upcoming several minutes. This form of information by its nature cannot be part of TREND forecast, because it would require issuing of many new SPECI messages continuously. The new type of message could be disseminated via discrete VHF frequency broadcast in voice form or via data link.

\section{Conclusion}

Thunderstorms pose a serious threat to every aircraft in flight. They are accompanied by severe turbulence and icing, heavy precipitation, lightning and possibly hail or other dangerous phenomena. For this reasons the training materials and aircraft operator safety policies require flight crews to avoid flying into the cumulonimbus clouds and discourage them from attempts to under-fly, over-fly or fly too close to these phenomena. However to assist in the avoidance, only limited sources of information about cumulonimbus position are provided to pilots. The situation can be made better by using today technologies with minimum costs. The increase of safety and reduction of unnecessary delays and fuel burn would benefit both passengers and aircraft operators and at last but not least would reduce the environmental impact.

\section{References}

[1] Petr Dvorak. Letecka meteorologie : ucebnice meteorologie pro piloty kvalifikace UL, GLD, PPL, CPL, ATPL a vsechny ostatni, kteri potrebuji odborne znalosti letecke meteorologie. Svet kridel, Cheb, 2010. ISBN 978-8086808-85-7.

[2] Manual of aeronautical meteorological practice. ICAO, Montreal, 2011. ISBN 978-92-9231-828-4.

[3] Aviation regulation 13: Meteorology, 2008. URL http://lis.rlp.cz/predpisy/ 
predpisy/dokumenty/L/L-3/data/print/L3_cely.pdf.

[4] Ian GILBERT. Airborne-weather-radar interpretation: Weather-radar operating principles and interpretation. 2005. URL http: //www. smartcockpit.com/docs/Airborne_ Weather_Radar_Interpretation.pdf.

[5] Metar/speci from lkpr, praha / ruzyne (czech republic): Time interval: from 07/05/2017 20:00 to 07/05/2017 22:00 utc, 2017. URL https : / / www. ogimet. com/ metars.phtml.en.

[6] Lukáš RONGE. iradarcz+ 2.6.3, 2017.

[7] Metar/speci from lkpr, praha / ruzyne (czech republic): Time interval: from 06/01/2018 08:00 to 06/01/2018 12:59 utc, 2017. URL https : / / www . ogimet. com/ metars.phtml.en.

[8] Lukáš RONGE. iradarcz+ 2.6.3, 2018.

[9] Robert MOORMAN. Unlocking the benefits of ads-b. Avionics Digital, 2016. URL http://interactive.aviationtoday.com/ avionicsmagazine/august-september$2016 /$ unlocking-the-benefits-of-ads-bin/. 